\title{
PROPAGAÇÃO DE IPECACUANHA POR ESTACAS DE RAIZ EM DIFERENTES CONDIÇÕES AMBIENTAIS E SUBSTRATOS
}

Fernanda Naiara Santos Ribeiro' ${ }^{\text {; }}$ Cristina Moll Hüther ${ }^{2}$; Thelma de Barros Machado ${ }^{3}$; Osmar Alves Lameira ${ }^{4}$; Carlos Rodrigues Pereira ${ }^{5}$

1Doutoranda do Programa de Pós-Graduação de Plantas Medicinais, Aromáticas e

Condimentares / Departamento de Agricultura, Universidade Federal de Lavras (f.naira@hotmail.com)

${ }^{2}$ Pós-doutoranda do Programa de Pós-Graduação em Engenharia de Biossistemas /

Departamento Engenharia Agrícola e Meio Ambiente, Universidade Federal

Fluminense.

${ }^{3}$ Professora Doutora do Departamento de Tecnologia Farmacêutica, Universidade Federal Fluminense.

${ }^{4}$ Pesquisador Doutor da Empresa Brasileira de Pesquisa Agropecuária, Centro de Pesquisa Agroflorestal da Amazônia Oriental, Embrapa Amazônia Oriental. ${ }^{5}$ Professor Doutor do Departamento Engenharia Agrícola e Meio Ambiente, Universidade Federal Fluminense.

Recebido em: 08/04/2017 - Aprovado em: 10/06/2017 - Publicado em: 20/06/2017 DOI: 10.18677/EnciBio_2017A86

\section{RESUMO}

O objetivo deste trabalho foi avaliar a brotação de estacas de raiz de plantas de ipecacuanha (Carapichea ipecacuanha) submetida a diferentes períodos do ano e a diferentes composições de substrato. Para a propagação da ipeca foram utilizados fragmentos de raízes com três centímetros de comprimento, alocadas em três diferentes substratos, ou seja, serragem, areia e substrato comercial (Basaplant®). Num primeiro ensaio, dois acessos de ipeca (819 e 825) foram colocados para brotar em substrato areia. Num segundo ensaio, raízes de ipeca sem identificação do acesso foram dispostas para brotar em substrato areia, no período de maio a agosto. Num terceiro ensaio, raízes de ipeca, também sem identificação do acesso (idem segundo ensaio), foram colocadas para brotar nos três substratos, no período de agosto a janeiro. Os ensaios de brotação foram realizados em estufa com sombreamento de $70 \%$ e as avaliações compreenderam o período de um ano. Em cada ensaio foi avaliado o número de brotações, o índice de velocidade de brotação e acompanhada a temperatura de cada substrato ao longo do período. As medidas de temperatura foram realizadas três vezes durante a semana de avaliação, em três horários do dia, ou seja, 06, 12 e 18 horas. A ipeca apresentou maior percentagem de brotação bem como maior índice de velocidade de brotação para o substrato areia, para o período de agosto a janeiro. O elemento temperatura influenciou a brotação, embora seu efeito tenha sido diferenciado de acordo com o tipo de acesso.

PALAVRAS-CHAVE: estaquia, planta medicinal, temperatura. 


\title{
IPECAC PROPAGATION BY CUTTINGS ROOT IN DIFFERENT AMBIENT CONDITIONS AND SUBSTRATES
}

\begin{abstract}
The aim of this study was to evaluate the budding root cuttings of ipecac plant (Carapichea ipecacuanha) submitted to different periods of the year and the different substrate compositions. For the propagation of ipecac root fragments were used with three centimeters in length, allocated to three different substrates, or are sawdust, sand, and commercial substrate (Basaplant®). In a first experiment, two accesses of ipecac (819 and 825) were put forth in sand substrate. In a second test, ipecac roots unidentified access were willing to sprout in sand, in the period from May to August. In a third trial, also unidentified roots of ipecac access (idem second test), have been put forth for the three substrates, from August to January. The sprouting assays were performed in oven with $70 \%$ shading and ratings understood the period of one year. In each test evaluated the number of shoots, the budding speed index and monitored the temperature of each substrate over the period. Temperature measurement was made three times a week evaluation in three times of the day, or is, 06, 12 and 18 hours. Ipecac showed a higher percentage of budding and sprouting higher speed index for sand substrate for the period from August to January. The temperature influence on the sprouting element, although its effect has been differentiated according to the type of access.
\end{abstract}

KEYWORDS: cuttings, medicinal plant, temperature.

\section{INTRODUÇÃO}

$\mathrm{Na}$ vegetação brasileira encontra-se uma grande diversidade de plantas medicinais, com princípios ativos de relevância econômica. Informações sobre os benefícios e usos dessas plantas foram compiladas por naturalistas europeus no século 19, principalmente pelo botânico francês Auguste de Saint-Hilare (1779-1853) (BRANDÃO et al., 2012). Essas plantas, com potencial medicinal sempre foram utilizadas pelos povos indígenas, no entanto, a partir da colonização do Brasil essas informações começaram a ser difundidas no "meio civilizado" (FERREIRA JÚNIOR et al., 2012).

A ipecacuanha (Carapichea ipecacuanha) é um arbusto perene, conhecido popularmente como ipeca, poaia, ipeca-verdadeira, poaia cinzenta, poaia legítima, ipeca-preta e ipeca-do-Mato-Grosso, pertencente à família Rubiaceae e tem como seu centro de origem o Brasil (LAMEIRA, 2002), no entanto, segundo OLIVEIRA et al. (2010), esta é uma espécie com três áreas distintas de distribuição: (i) a faixa de extensão do Atlântico; (ii) a extensão da Amazônia e (iii) a extensão da América Central e Colômbia. O grande potencial econômico é devido ao valor farmacológico presente nas raízes (FERREIRA JÚNIOR et al., 2012), parte da planta onde se concentram altos teores de emetina e cefalina (BRANDÃO et al., 2012), o quê confere à planta um poder emético e amebicida (OTONI et al., 2015). 
É uma espécie medicinal de potencial econômico, a raiz é obtida do extrativismo, sendo cada vez mais rara no habitat natural como em sub- bosque de florestas tropicais (LAMEIRA, 2002; OLIVEIRA et al., 2010). A C. ipecacuanha é uma representante desse grupo que apresenta risco de extinção, pois apresenta baixas taxas de produção de sementes e de germinação (OLIVEIRA et al., 2010) e também com o desmatamento, tem havido uma redução da disponibilidade de hábitat adequado, além do fato da coleta descontrolada, pelas populações nativas, ter acelerado ainda mais o declínio demográfico das populações selvagens de ipecacuanha (OLIVEIRA et al., 2010; OTONI et al., 2015; CNCFLORA, 2017).

Apesar do fato de que a ipecacuanha tenha sido utilizada como planta medicinal ao longo da história, há falta de informações sobre esta espécie (FERREIRA JÚNIOR et al., 2012). A maioria dos trabalhos desenvolvidos são focados em aspectos botânicos e estudos farmacológicos, e há também vários trabalhos sobre protocolos de cultivo in vitro. Há diversos trabalhos que referenciam o ambiente de ocorrência natural das espécies, mas no que diz respeito a aspectos agronômicos pouco se tem feito para que essa espécie seja incluída em programas de cultivo e fomento. Estudos acerca de propagação por estaquia, que envolvam a parte radicular, também são escassos.

Para a ipeca faltam informações quanto às fases do seu ciclo biológico, como propagação e crescimento (OTONI et al., 2015) e principalmente a influência de fatores abióticos, como a utilização de diferentes substratos, temperatura do solo, bem como diferentes tipos de sombreamento, mesmo que de forma artificial. Essa carência de informações torna necessária a condução de estudos com a espécie em busca de respostas quanto ao seu desenvolvimento e crescimento sob a influência de tais variações.

Para que possa haver a reintrodução dessa espécie em áreas nativas na região do estado do Rio de Janeiro, bem como seu cultivo de forma controlada, a fim de, futuramente, possa se tornar uma alternativa de produção de forma sustentável e economicamente viável, mais estudos são de grande interesse. Assim, o objetivo desse trabalho foi avaliar a brotação de estacas de raízes de ipecacuanha (Carapichea ipecacuanha) em diferentes substratos.

\section{MATERIAL E MÉTODOS}

O material vegetal foi obtido do Banco Ativo de Germoplasma de ipeca ex-situ do horto de plantas medicinais da Embrapa Amazônia Oriental, Belém - PA. O experimento foi conduzido no campus Gragoatá da Universidade Federal Fluminense, no município de Niterói-RJ, latitude de $22^{\circ} 54^{\prime} 00^{\prime \prime} \mathrm{S}$, longitude de $43^{\circ}$ $08^{\prime} 00^{\prime \prime}$ W e altitude de 8 metros, com uma temperatura média anual de $23^{\circ} \mathrm{C}$, em casas de vegetação pertencentes ao projeto "Banco Ativo de Germoplasma de Ipecacuanha".

O ensaio de brotação da ipeca foi realizado em casa de vegetação com sombreamento de $70 \%$, conforme recomendado por LAMEIRA (2002). As avaliações foram realizadas de janeiro de 2014 a janeiro de 2015.

Para a propagação da ipeca foram utilizados fragmentos (estacas) de raízes com $3 \mathrm{~cm}$ de comprimento, obtidas de plantas com dois anos de idade com raízes de 25 centímetros de comprimento e diâmetro entre 1,5 a 2 centímetros, alocadas em bandejas de plástico perfuradas, dispostas na posição horizontal e enterradas a 2 centímetros de profundidade. $O$ tamanho de $3 \mathrm{~cm}$ ficou entre o tamanho de estaca recomendado por LAMEIRA (2002), que é de $5 \mathrm{~cm}$, e o recomendado por TEIXEIRA (2008), que realizou experimentos com estacas de $2 \mathrm{~cm}$ de comprimento. 
O material vegetal foi acondicionado em três diferentes substratos: serragem (obtida de madeiras diversas), areia lavada e substrato comercial (Basaplant $\circledast$ ). Ao longo do período experimental foram realizadas irrigações periódicas, duas vezes ao dia, com uso de aspersores suspensos, acionados automaticamente, mantendo a umidade próxima à capacidade de campo.

Em cada ensaio foram avaliados o número de brotação, o índice de velocidade de brotação e a temperatura de cada substrato. A medida de temperatura foi realizada em dias intercalados, em três horários do dia, a saber: 06, 12 e 18 horas. As temperaturas foram medidas por meio de um termômetro de solo.

O índice de velocidade de brotação foi calculado pelo somatório do número de estacas brotadas a cada dia (o número total contado em cada amostragem foi subtraído do número total da contagem anterior), dividido pelo número de dias decorridos entre o plantio e data da contagem de brotação, de acordo com a Equação 1, proposta por MAGUIRE (1962), adaptada para brotação de estacas.

IVB $=\left(B_{1} / B_{1}\right)+\left(B_{2} / N_{2}\right)+\left(B_{3} / N_{3}\right)+\ldots+\left(B_{n} / N_{n}\right)$

em que:

IVB = índice de velocidade de brotação;

$\mathrm{B}_{1}, \mathrm{~B}_{2}, \mathrm{~B}_{3}, \ldots, \mathrm{Bn}=$ número de brotações computadas na primeira, segunda, terceira e última contagem;

$N_{1}, N_{2}, N_{3}, \ldots, N n$ = número de dias do plantio das estacas à primeira, segunda, terceira e última contagem.

No período de janeiro a maio de 2014 foi conduzido o experimento de brotação utilizando dois tipos de acessos de ipeca (819 e 825), sendo esses representantes do material vegetal oriundo de Costa Marques e Cacoal (Rondônia), respectivamente. $O$ delineamento estatístico foi inteiramente casualizado, utilizando dois acessos, em quatro blocos com 100 estacas cada.

No período de agosto de 2014 a janeiro de 2015 foi conduzido um experimento de brotação inteiramente casualizado utilizando três substratos, serragem, areia e substrato comercial (Basaplant $\circledast$ ), sendo também composto por quatro blocos cada contendo 100 estacas por bloco. Os dados coletados foram submetidos aos testes de normalidade e homogeneidade e as médias dos tratamentos comparadas pelo teste Tukey a $5 \%$ de probabilidade utilizando o programa estatístico Assistat® $\AA^{\circ}$.

\section{RESULTADOS E DISCUSSÃO}

Analisando 0 índice de velocidade de brotação apenas no substrato areia pode-se verificar que o acesso 825 se sobressaiu sobre o acesso 819 , obtendo um índice de velocidade de brotação de 1,05, sendo superior estatisticamente ao acesso 819, que alcançou um índice de velocidade de brotação de 0,30 (Figura 1A). 

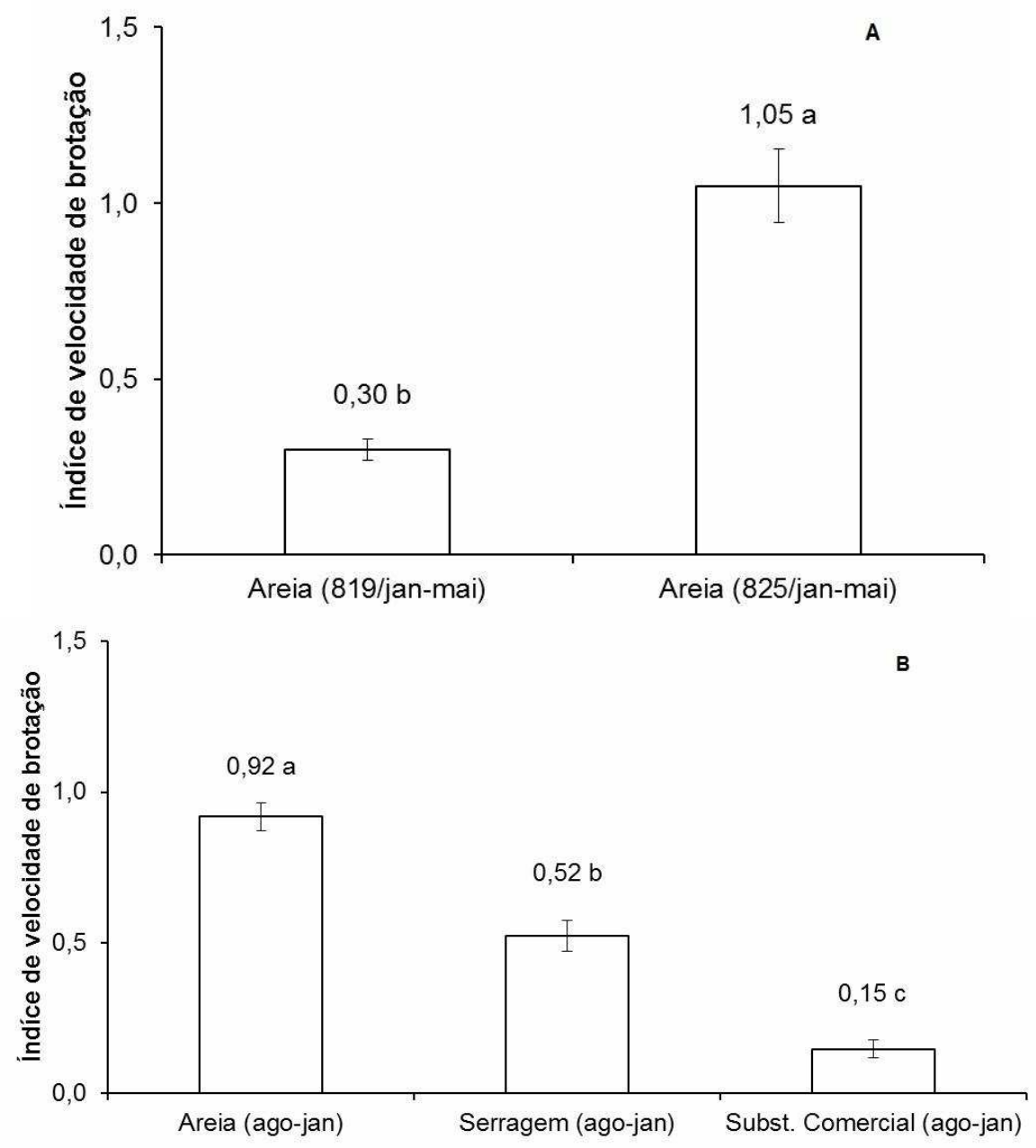

FIGURA 1. Índice de velocidade de brotação (IVB) de acessos de ipeca $(A)$, e plantados em diversos tipos de substrato $(B)$.

Para o índice de velocidade de brotação no período de ensaio compreendido entre agosto de 2014 e janeiro de 2015 nos substratos areia, serragem e Basaplant ${ }^{\circledR}$ foram observadas diferenças significativas entre os mesmos, com os valores 0,$92 ; 0,52$ e 0,15 , respectivamente (Figura 1B).

A maior porcentagem de brotação para o acesso 825 também foi refletido pelo índice de velocidade de germinação e isso pode ter sido influenciado pela temperatura do substrato, pois conforme dados da temperatura do substrato areia para esse período, a temperatura média estava em $22^{\circ} \mathrm{C}$ no substrato, e o acesso 825 possui no seu local de origem uma média de temperatura do ar equivalente a $26^{\circ} \mathrm{C}$, significando que no solo a temperatura do local de origem pode ser próxima a $22^{\circ} \mathrm{C}$, devido ao sombreamento do ambiente (sub-bosque). Assim, pode-se inferir que a temperatura do solo no experimento esteve bem próxima de seu local de origem, para esse período. Para o acesso 819, em que seu local de origem, a temperatura média do ar é de $34^{\circ} \mathrm{C}$, portanto necessitaria uma temperatura maior para um sucesso maior na brotação.

Embora esses acessos estivessem alocados no município de Belém - PA suas origens pertencem ao estado de Rondônia, onde há essas oscilações de 
temperatura entre os dois municípios, pois Costa Marques está próximo a divisa com a Bolívia, o relevo pertence à Depressão da Amazônia Meridional, além de apresentar uma transição entre floresta aberta e savana (UFSC, 2011). Assim, esses fatores ambientais podem ter sido transmitidos pela memória epigenética (COSTA \& PACHECO, 2013) desses acessos, o que favoreceu a brotação no acesso 825.

Entre os dois tipos de acesso de ipeca utilizados, a maior percentagem de brotação foi alcançada pelo acesso 825, chegando ao final da avaliação com $51,67 \%$ de brotação da raiz e somente $26,67 \%$ de brotação da raiz para o acesso de número 819 (Figura 2A).


FIGURA 2. Percentagem total de brotação com os desvios padrão de acessos de ipeca $(A)$, e plantados em diversos tipos de substrato $(B)$.

Avaliando a brotação da raiz dos outros acessos utilizados (local de origem não identificado), no período de agosto de 2014 a janeiro de 2015, comparando-se diferentes substratos, os maiores valores foram alcançados no substrato tipo areia, sendo esse superior ao substrato serragem e ao substrato comercial (Basaplant ${ }^{\circledR}$ ), chegando ao final da avaliação com valores de percentagem de brotação de 83,33 para areia, 45,00\% para serragem e $13,33 \%$ para Basaplant ${ }^{\circledR}$ (Figura $2 \mathrm{~B}$ ).

Segundo LARCHER (2000), no caso da brotação, há uma relação entre as condições climáticas e a percentagem da mesma, visto que há um mecanismo de regulação que evita a brotação em condições desfavoráveis. Algumas espécies brotam em temperaturas elevadas, enquanto outras somente brotam em baixas temperaturas e XIA et al., (2015) também enfatizam que a posição dos cortes pode 
influenciar na brotação. No caso do presente ensaio, período de maior temperatura, que foi de agosto a janeiro de 2015, o que coincidiu com a avaliação.

COELHO et al., (2013) verificaram uma maior percentagem de brotação da ipeca quando utilizaram o substrato areia. Isso é devido à menor capacidade de retenção de água, (maior drenagem) alta densidade e baixa temperatura. Ao longo do experimento a espécie teve uma brotação desuniforme e requereu, em média, um período de 30 dias para ter a primeira brotação, independentemente do período do ano que foi realizado o processo de propagação da espécie (Figura 3A e 3B). De forma geral, o menor período para ocorrer a brotação foi de oito dias e o maior período, para brotação de 140 dias.
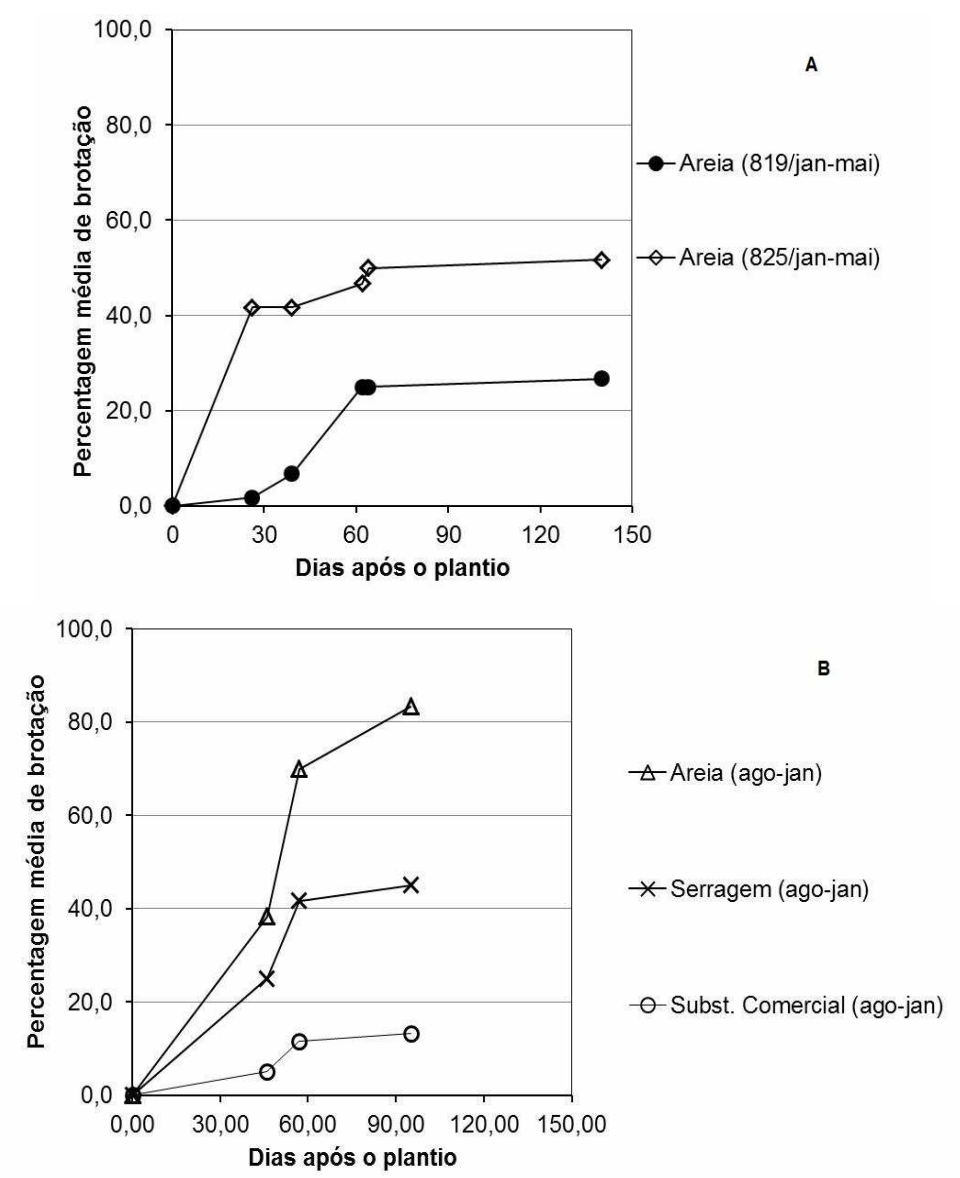

FIGURA 3. Evolução da percentagem média de brotação de acessos de ipeca (A), plantados em diversos tipos de substrato (B).

Sabe-se que nessa espécie, nas condições ambientais da região da Amazônia Oriental, o enraizamento e formação da parte aérea da planta de ipeca pode ocorrer com um mínimo de 20 dias após o plantio (LAMEIRA, 2002), no entanto nas condições realizadas nesse experimento houve um acréscimo de dez dias, além de uma brotação desuniforme, provavelmente devido à mudança de ambiente.

Assim, nesse experimento, as raízes de ipeca levaram menos tempo para brotação em temperaturas mais baixas, entretanto, nesse período ocorreu menor 
evolução da percentagem de brotação. Portanto, os dados obtidos entre os diferentes tratamentos demostraram que as melhores respostas foram alcançadas quando submetidos a uma faixa de temperatura entre $17^{\circ} \mathrm{C}$ e $26^{\circ} \mathrm{C}$ e com substrato tipo areia.

Para o período de janeiro de 2014 a janeiro de 2015 os valores das médias de temperatura nos horários de 6:00, 12:00 e 18:00 h, a $5 \mathrm{~cm}$ de profundidade nos substratos demonstraram a oscilação da temperatura média ao longo do ano (Figura 4).

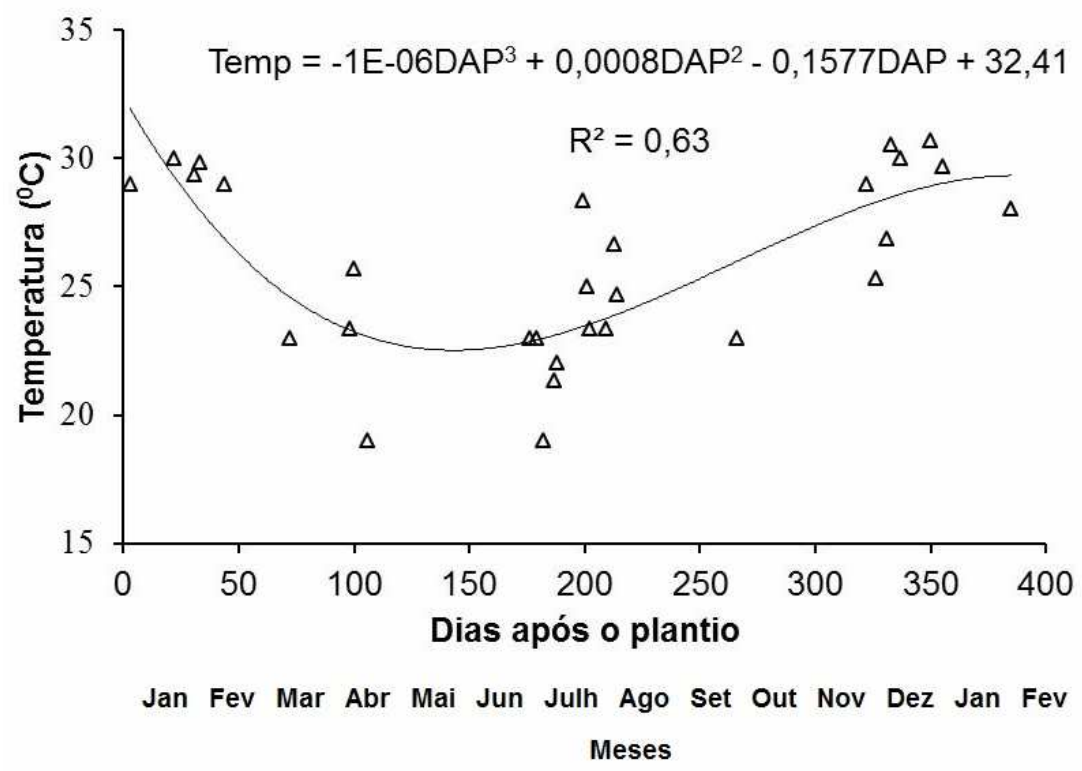

FIGURA 41. Evolução dos valores médios de temperatura dos substratos, medidos às 6:00, 12:00 e 18:00 horas.

Houve um decréscimo de temperatura no decorrer dos meses de janeiro a junho e um acréscimo a partir do mês de julho de 2014 até janeiro de 2015. Nos meses de janeiro, fevereiro e março de 2014, a média dos três horários chegou a uma temperatura máxima de $30^{\circ} \mathrm{C}$, posteriormente nos meses de maio a outubro, a temperatura média ficou entre 23 e $27^{\circ} \mathrm{C}$ e nos meses de novembro de 2014 a janeiro de 2015, a temperatura média permaneceu entre 27 e $30^{\circ} \mathrm{C}$.

No período com médias de temperatura mais baixas $\left(22^{\circ} \mathrm{C}\right)$, entre os meses de maio a agosto ocorreram as menores percentagens de brotação nos ensaios realizados. Isso corrobora com trabalho realizado por COELHO et al., (2013) que mostraram que durante um período de sete dias, temperaturas abaixo de $25^{\circ} \mathrm{C} \mathrm{em}$ experimento na fase de campo, ocasionam danos às estacas de raiz da ipeca.

Fatores ambientais influenciam na divisão celular e na expansão celular, regulando assim o crescimento e o desenvolvimento das plantas (OKELLO et al., 2016). Assim, tanto a temperatura como a percepção e a qualidade de luz possuem importante função regulatória no metabolismo das estacas (CUNHA et al., 2009 PACHOLCZAK et al., 2017) e MABIZELA et al., (2017) também salientam que em determinadas estações do ano a sobrevivência das estacas é afetada, dependendo da espécie e que também é importante observar qual o melhor período ou estação para fazer a coleta do material de propagação, pois pode variar o potencial de enraizamento. 
A estratificação das estacas em baixas temperaturas inibe a formação de raízes e impede a brotação. Segundo LAMEIRA (2002), a ipeca é uma planta que se propaga em determinadas condições, e a temperatura elevada é um exemplo de condições energéticas que a espécie exige e tolera bem. No entanto, os fatores endógenos também influenciam na sobrevivência das estacas, como por exemplo, o teor de carboidrato (DIAS et al., 2013).

Entre os substratos, aquele que apresentou maior variação de temperatura foi a areia, apresentando, às $6: 00 \mathrm{~h}$, a menor temperatura, seguida do substrato comercial e da serragem. A amplitude térmica máxima (diferença entre as temperaturas de $12: 00$ e 06:00 horas) apresentada pela areia foi de $6,8^{\circ} \mathrm{C}$, seguida pela serragem $\operatorname{com} 6,7^{\circ} \mathrm{C}$ e pelo substrato comercial Basaplant ${ }^{\circledR}$ com $6,3^{\circ} \mathrm{C}$. Às 18:00 horas a areia apresentou também a maior temperatura, seguida da serragem e do substrato comercial Basaplant ${ }^{\circledR}$ (Figura 5). Isso demonstra que a areia apresentou uma melhor condutividade térmica, em relação aos demais substratos.

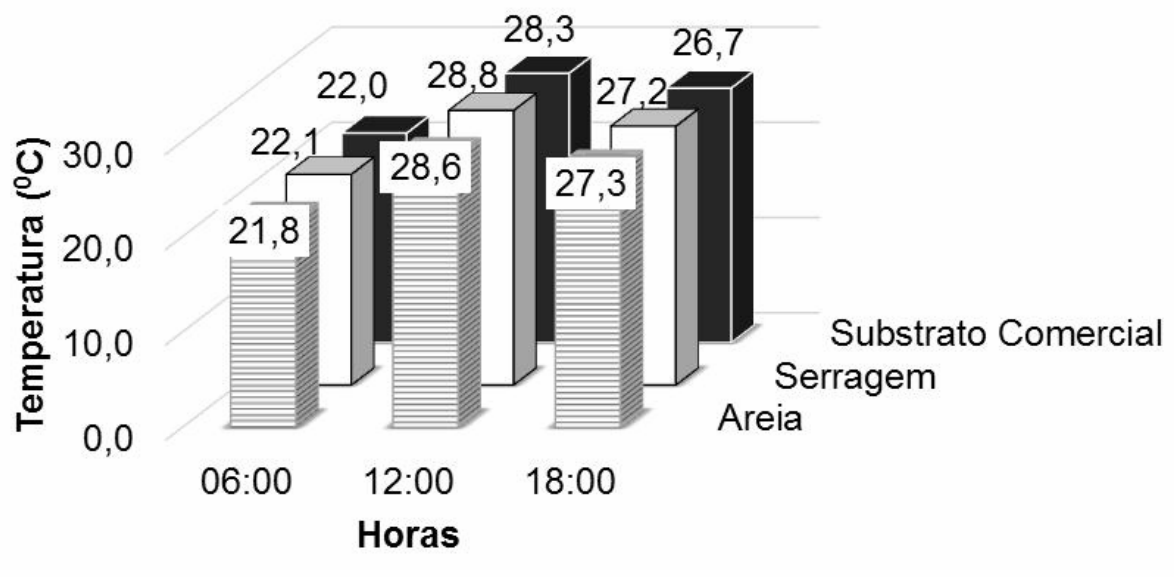

曰Areia 口Serragem - Substrato Comercial

FIGURA 5. Médias da temperatura dos substratos areia, serragem e substrato comercial, relativas às 6:00, 12:00 e 18:00 horas.

As flutuações de temperatura ao longo dos ensaios pode ser a razão da uniformidade não homogênea verificada na brotação da ipeca, além do fator substrato. Essas flutuações podem ter ocasionado alterações nos processos fisiológicos dessas estacas, pois segundo HAWERROTH et al., (2010), baixas temperaturas agem em duplo processo, ou seja, inicialmente contribuem para a paralisação do crescimento, aclimatação e posteriormente atuam na superação desse estado, ou seja, as plantas individualmente podem aclimatar-se às mudanças periódicas no ambiente (TAIZ et al., 2017).

De forma geral, a ipeca apresentou maior percentagem de brotação para o substrato areia, em relação aos outros substratos, sendo o período de agosta a janeiro o mais propício para esse parâmetro em relação aos outros períodos. Para o índice de velocidade de brotação, a areia também foi o melhor substrato e o período, aquele de maio a agosto, nas condições ambientais de brotação do local de estudo.

Em termos de substrato, a areia foi seguida da serragem e por último ficou o substrato comercial Basaplant ${ }^{\circledR}$ tanto para percentagem de brotação quanto para 0 
índice de velocidade de brotação. Dessa forma, a brotação de estacas de raízes de ipecacuanha foi afetada pelo tipo de substrato.

\section{CONCLUSÕES}

O índice de velocidade de brotação, a percentagem de brotação total e a percentagem média de brotação de acessos de ipecacuanha tiveram valores superiores no substrato areia, em comparação com os demais substratos testados sendo, por esse estudo, o mais indicado para essa atividade.

A brotação de estacas de raízes de ipecacuanha foi afetada confome o tipo de substrato, e pode ter sido influenciada por fatores como a temperatura, sazonalidade e a origem dos acessos.

\section{AGRADECIMENTO}

Ao Conselho Nacional de Desenvolvimento Científico e Tecnológico, à Coordenação de Aperfeiçoamento Pessoal de Nível Superior, à Empresa Brasileira de Pesquisa Agropecuária - Embrapa Amazônia Oriental.

\section{REFERÊNCIAS}

BRANDÃO, M. G. L.; PIGNAL, M. ; ROMANIUC, S. ; GRAEL, C. F. F. ; FAGG, C. F. F. Useful Brazilian plants listed in the field books of the French naturalist Auguste de Saint-Hilaire (1779-1853). Journal of Ethnopharmacology, v. 143, n. 2, p. 488500, $2012 . \quad$ Disponivel em: <https://www.researchgate.net/publication/263353679_Useful_Brazilian_plants_listed in_the_field_books_of_the_french_naturalist_Auguste_de_Saint-Hilaire_17791853> . doi: http://dx.doi.org/10.1016/j.jep.2012.06.052

COELHO, M. F. ; TEIXEIRA, V. ; RAB; ALBUQUERQUE, M. C. . Propagação da poaia (Psychotria ipecacuanha) em diferentes substratos e posicionamento das estacas.Horticultura Brasileira, v. 31, n. 3, p. 467-471, 2013. Disponivel em: <http://www.scielo.br/scielo.php?script=sci_arttext\&pid=S010205362013000300020> . doi: http://dx.doi.org/10.1590/S0102-05362013000300020

COSTA, E. B. O. ; PACHECO, C. Epigenética: regulação da expressão gênica em nível transcricional e suas implicações. Ciências Biológicas e da Saúde, v, 34, n. 2, p. 125-136, 2013. Disponível em: http://www.uel.br/revistas/uel/index.php/seminabio/article/viewFile/5142/13877. DOI: 10.5433/1679-0367.2013v34n2p125.

CUNHA, A. C. M. C. M. ; PAIVA, H. N. ; LEITE, H. G. ; BARROS, N. F. ; LEITE, F. P. Relações entre variáveis climáticas com produção e enraizamento de miniestacas de eucalipto. Revista Árvore, v. 33, n. 2, p. 195-203, 2009. Disponivel em: <http://www.scielo.br/scielo.php?script=sci_arttext\&pid=S010067622009000200001> doi: http://dx.doi.org/10.1590/S0100-67622009000200001.

CNCFLORA. Carapichea ipecacuanha in Lista Vermelha da flora brasileira versão 2012.2 Centro Nacional de Conservação da Flora. Disponível em <http://cncflora.jbrj.gov.br/portal/pt-br/profile/Carapichea ipecacuanha>. Acesso em 28 abril 2017. 
DIAS, J.PT.; TAKATA, W.H.S.; TAKAHASHI, K.; ONO, O.E. Propagação de figueira com estacas de diferentes diâmetros. Revista Trópica - Ciências Agrárias e Biológicas, v.7, n.1, p. 52-57, 2013. Disponível em < http://www.periodicoseletronicos.ufma.br/index.php/ccaatropica/index>. Doi https://doi.org/1982-4831.

FERREIRA JUNIOR, W. S. ; CRUZ, M. P. ; SANTOS, L. L. ; MEDEIROS, M. F. T. Use and importance of quina (Cinchona spp.) and ipeca (Carapichea ipecacuanha (Brot.) L. Andersson): Plants for medicinal use from the 16th century to the presente. 2012. Journal of Herbal Medicine. v. 2, n. 4, p.103-112, 2012. Disponivel em: <http://www.sciencedirect.com/science/article/pii/S2210803312000632> . doi: http://dx.doi.org/10.1016/j.hermed.2012.07.003.

HAWERROTH, F. J. ; HERTER, F. G. ; PETRI, J. L. ; LEITE, G. B. ; PEREIRA, J. F. M. Dormência em frutíferas de clima temperado. Embrapa Clima Temperado. Ministério da agricultura, Pecuária e abastecimento, Documento 310, p.1-56 2010. Disponivel em: <https://www.embrapa.br/busca-de-publicacoes//publicacao/884602/dormencia-em-frutiferas-de-clima-temperado> .

LAMEIRA, O. A. Cultivo da Ipecacuanha [Psychotria ipecacuanha (Brot.) Stokes]. EMBRAPA. Circular técnica Belém: Embrapa Amazônia Oriental, v. 28, p. 1-4, 2002. Disponivel em: <https://www.infoteca.cnptia.embrapa.br/handle/doc/405771> .

LARCHER, W. Ecofisiologia vegetal. 2000. São Carlos: RiMa Artes e Textos. p. 531.

MABIZELA, G.S.; SLABBERT, M.M.; BESTER, C. The effect of rooting media, plant growth regulators and clone on rooting potential of honeybush (Cyclopia subternata) stem cuttings at different planting dates. South African Journal of Botany, v.110, p.75-79, 2017. Disponível em <http://www.sciencedirect.com/science/article/pii/S0254629915325904>. Doi https://doi.org/10.1016/j.sajb.2016.02.200

MAGUIRE, J. D. Speed of germination aid in selection and evaluation for seedling emergence and vigor. Crop Science, v. 2, n.1, p.176-177,1962. Disponivel em: < https://dl.sciencesocieties.org/publications/cs/abstracts/2/2/CS0020020176/> . Doi: doi.org/10.2135

OKELLO, R. C.O.; de VISSER, P. H. B. ; HEUVELINK, E. ; MARCELIS, L. F. M. ; STRUIK P. C. Light mediated regulation of cell division, endoreduplication and cel expansion. Environmental and Experimental Botany, v. 121, p. 39-47, 2016 Disponivel em: < http://www.sciencedirect.com/science/article/pii/S0098847215000684> . doi: http://dx.doi.org/10.1016/j.envexpbot.2015.04.003

OLIVEIRA, L. O.; VENTURINI, B. A. ; ROSSI, A. A. B. ; HASTENREITER, S. S. Clonal diversity and conservation genetics of the medicinal plant Carapichea ipecacuanha (Rubiaceae).Genetics and Molecular Biology, v. 33, n.1 , p. 86-93, 
2010. Disponivel em: <http://www.scielo.br/scielo.php?script=sci_arttext\&pid=S141547572010000100016> . doi: http://dx.doi.org/10.1590/S1415-47572009005000096.

OTONI,W.C; SILVA, M.L.; AZEVEDO, A.A.; CARVALHO, I.F.; ROSSI, A. A. B.; CASTRILLON, S.I. Morfoanatomia dos sistemas gemíferos de poaia (Carapichea ipecacuanha (Brot.) L. Andersson) - Rubiaceae. Revista Fitos, v.9, n.1, p. 9-17, 2015. Disponível em: <http://revistafitos.far.fiocruz.br/index.php/revistafitos/article/view/196/pdf_53>. doi 10.5935/2446-4775.20150001.

PACHOLCZAK, A.; JEDRZEJUK, A.; SOBCZAK, M. Shading and natural rooting biostimulator enhance potential for vegetative propagation of dogwood plants (Cornus alba L.) via stem cuttings. South African Journal of Botany, v.109, p.3441, 2017. Disponível em <http://www.sciencedirect.com/science/article/pii/S0254629916326011>. Doi https://doi.org/10.1016/j.sajb.2016.12.009.

TAIZ, L.; ZEIGER, E.; MOLLER, I.M.; MURPHY, A. Fisiologia e Desenvolvimento Vegetal. Artmed, 6 ${ }^{\mathrm{a}}$ ed. Porto Alegre-RS, 888 p. 2017.

TEIXEIRA, V. A. . 2008. Memória cultural e propagação de ipeca [Psychotria ipeca (Brot.) Stoves] em Cáceres - MT. Cuiabá: UFMT. 58 p. (Dissertação de Mestrado). Disponivel em: < http://ivros01.livrosgratis.com.br/cp089529.pdf>.

UFSC - Universidade Federal de Santa Catarina, Centro Universitário de Estudos e Pesquisas sobre Desastres - Atlas brasileiro de desastres naturais 1991 a 2010. 2011. CEPED UFSC Rondônia: p.1-45. Disponivel em: < http://150.162.127.14:8080/atlas/atlas.html>.

XIA, Q.; WU, W-C.; TIAN, K.; JIA, Y-Y.; WU, X.; GUAN, Z.; TIAN, X-J. Effects of different cutting traits on bud emergence and early growth of the Chinese vegetable Toona sinensis. Scientia Horticulturae, v.190, p. 137-143, 2015. Disponível <http://www.sciencedirect.com/science/article/pii/S0304423815002289>. Doi https://doi.org/10.1016/j.scienta.2015.04.026. 